\title{
Armenia at a Strategic Crossroads
}

\section{Richard Giragosian *}

Since the collapse of the Soviet Union, independent Armenia has struggled to forge new institutions of statehood and overcome a daunting set of economic, political, and social challenges. For Armenia, the course of economic and political reform was especially difficult, as the country has had to confront the effects of a severe earthquake, a war with neighboring Azerbaijan, and the imposition of a virtual blockade on trade by Turkey and other neighbor states. Armenia still faces serious challenges, however, including incomplete democratic reform and uneven economic development.

There are four recent trends which, when combined with the limited capacity of the Armenian government to respond to these broader challenges, may pose new threats to security and stability in Armenia. Moreover, these trends now constitute a crucial test for Armenia; depending on the government's response, they may very well determine the future political and economic development of the country. These four trends include:

- Widening disparities in wealth and income, which is matched by a sharp political polarization

- An increasingly unsustainable economic system, plagued by unresolved structural deficiencies, including a dangerous reliance on remittances

- An inadequate response to the broader global financial and economic crisis, exacerbated by spikes in prices for energy and food, by a reduction in the flow of remittances and a contraction of key sectors, such as the construction and mining sectors

- An overall lack of legitimacy, rooted in an unresolved and lingering political crisis and bolstered by a new political "awakening” after years of political apathy and civic disengagement.

\section{Widening Disparities in Wealth \& Income}

Although Armenia's record of economic reform in recent years has been fairly impressive, most assessments of the nation's economy concentrate exclusively on Armenia's statistical record of double-digit economic growth and the gradual, yet consistent, decline in national poverty. Yet one of the more negative aspects of Armenia's economic reality is the "paradox" of economic growth, whereby several years of significant growth have resulted in an uneven distribution of wealth and improved living standards throughout the overall population. Moreover, widening disparities in wealth and income have led to an increasingly serious socioeconomic divide.

Richard Giragosian is the Director of the Armenian Center for National and International

Studies (ACNIS), an independent think tank based in Yerevan, Armenia. 
There is also a geographic aspect to this socioeconomic divide, along urban-rural lines. In general, Armenia displays an over-concentration of economic activity and opportunity in urban centers and the capital. This division has fostered more pronounced regional and rural income inequalities and has been exacerbated by a wide variance in the quality of and access to essential public goods such as health, education, and other social services. The infrastructural divide between regions and urban centers has also encouraged greater migration to cities from the country's outlying rural areas. This rural-urban divide is also reflected in the course of political development and democratization, as power is overwhelmingly concentrated in the capital.

\section{Armenia's Political Polarization}

Over the past year, Armenia has experienced a widening polarization in politics, defined by a newly united political opposition and an increasingly unpopular government. This split has been exacerbated by the socio-economic divide between a small wealthy ruling elite and a much larger population whose prospects are hindered by limited economic opportunity and even less political power. More specifically, this polarization has been most clearly demonstrated by the powerful role of Armenia's small wealthy political elite, the so-called "oligarchs," who exercise not only commercial and economic power through commodity-based cartels and virtual monopolies, but who have also acquired political power after becoming parliamentary deputies. Their political position and influence have allowed them to emerge as powerful vested interests, wielding influence over the formulation of public policy and exerting leverage over the implementation of economic and political reforms. Left unchecked, their wealth and political power serve to threaten democratization and the rule of law and allow them to further consolidate and protect their informal networks of power.

Thus, there is a now obvious link between economics and politics in terms of governance, affirmed by the tendency to implement (or distort) economic reforms based on political considerations or vested interests. Although such a linkage is a natural feature of many countries, in the case of the Armenian model, the combination of a closed political system, a lack of effective systemic checks and balances, and the weak and arbitrary rule of law exposes the processes of economic and political reform to even greater pressure and undue political influence. ${ }^{1}$

\section{An Unsustainable Economic System}

The vulnerability of the Armenian economy-despite the relative "incubation" of the economy as a result of closed borders and limited links to the broader global economy-is rooted in its inherent structural fragility. This fragility is composed of three elements:

1 International Crisis Group (ICG), “Armenia: Picking up the Pieces,” ICG Europe Briefing No. 48 (8 April 2008). 
- A dangerous dependence on the influx of remittances, or money from Armenians working abroad

- A narrow reliance on the country's service, commodity, and construction sectors as the main drivers of economic growth

- A closed "oligarchic" economic network centered on several informal commodity-based cartels or semi-monopolies.

The Armenian government has traditionally exploited its record of strong statistical economic growth as a source of legitimacy, both externally and domestically. Crippled by a lack of popular support and hindered by a record of tainted elections, the Armenian authorities have used the nation's strong record of economic growth to obscure the ruling party's lack of a mandate to govern. ${ }^{2}$ But the combination of structural fragility, entrenched corruption, and incomplete reform is now posing a threat to the economic system itself, raising questions about whether it can sustain itself in the face of mounting challenges.

\section{The "Cancer of Corruption"}

Corruption in Armenia represents a significant impediment to both equitable economic development and good governance. Over the long term, corruption weakens the state and its institutions by undermining an already meager degree of state legitimacy and public trust, and limits the government's financial capacity by withholding essential tax revenue. While the shortfall in tax collection and other corruption-related activities impose inherent limits on state funding for strategic social programs - such as education, health care, and pensions-it also strains the government's capacity to meet its even more immediate budgetary obligations and normal operational needs.

There are some important measures that the Armenian state can adopt in order to combat the "cancer of corruption." However, these steps must be bolstered by an overall strengthening of the rule of law, and will require the implementation of a careful combination of measures designed to enhance the authority and independence of state structures, starting with a focus on creating and strengthening regulatory agencies and bodies.

In contrast to blanket measures endowing the state with more powers, however, the state's fight against corruption must be carried out by more independent oversight bodies empowered to supervise privatization and the emerging securities markets, ensure greater competition, and to regulate monopolies, cartels, or trusts. Such regulatory bodies should be independent from (but accountable to) the government and governed by strict standards of transparency, accountability, and oversight. But given the reality of today's Armenia, these measures can only be effective within a new context of "good governance," which carries the prerequisites of transparency, ethics, accountability, and competent administration. These prerequisites are notably lacking in Armenia, however, as the country remains defined by an overly dominant executive

2 Ibid. 
branch that tends to marginalize the parliament and intimidate the judiciary. Thus, for Armenia, institutions matter, and judicial independence and meritocracy must replace favoritism and cronyism in order to develop a more resilient democracy and a more open and free market economy.

\section{Inability to Address the Impact of the Broader Global Economic Crisis}

Already weakened by a pronounced lack of legitimacy, and beset by a prolonged political crisis of confidence, the Armenian government is facing a new challenge from the global financial and economic crisis. The global crisis has already led to a sharp decline in remittance flows, which provide an essential cash influx for most Armenians; a sudden downturn in the country's mining sector, prompting the loss of several thousand jobs; and a dramatic reduction in the level of Russian investment in the construction industry.

But most troubling is the Armenian government's rather shortsighted refusal to even recognize the country's vulnerability to the global economic crisis. Although government officials admit that economic activity has already contracted considerably, they have tended to downplay both the significance and the severity of the crisis. The Armenian government's first response to the crisis was neither to step up the fight against corruption nor even to tackle the deeply-rooted problem of low tax collection. Instead, Armenia turned to outside sources for urgent help. In January 2009, the World Bank announced that it would more than double its lending to Armenia, from USD 220 million to at least USD 525 million over a four-year period. ${ }^{3}$

In addition, Armenia also secured a USD 500 million "stabilization credit" from Russia, designed to ease the initial impact of the global crisis. But this external assistance is not a panacea for the country's economic troubles, especially since the loans will not address any of the more serious structural problems and weaknesses of the Armenian economy. Moreover, by failing to confront the closed nature of the country's economic system, which is dominated by oligarchic commodity-based cartels, the unresolved obstacles from entrenched corruption and corporate tax evasion will only continue to impede real economic reform. Thus, in the economic sense, the Armenian government is merely deferring, but not defeating, the challenges of distorted economic growth and deformed economic structures. ${ }^{4}$

\section{A Lack of Legitimacy}

For much of the last decade, the Armenian population had grown accustomed to flawed elections, economic inequality, and a lack of democratic governance. And over time, as the population became increasingly disengaged from politics, a pronounced general

3 Richard Giragosian, "Weathering the Storm: A Commentary on Armenia and the Global Economic Crisis,” ArmeniaNow.com (6 February 2009).

4 Richard Giragosian, "Weathering the Storm: A Commentary on Armenia and the Economics of Power,” ArmeniaNow.com (13 February 2009). 
state of apathy took hold in Armenia. ${ }^{5}$ But with the transition of power from former President Robert Kocharian to his chosen successor, Serzh Sarkisian, the apathy of the Armenian population rapidly dissipated. Although the "awakening" of the Armenian people was triggered by the February 2008 presidential election, it was not the actual vote that was significant, but rather the process of the election campaign that was more revealing, particularly because of the uneven playing field and the closed nature of the Armenian political system. ${ }^{6}$

In the wake of the outpouring of demonstrations and public protests over the presidential election, the post-election crisis in Armenia pointed to two specific facts about the political climate in Armenia. First, the post-election crisis is far from being over; in fact, it is still well under way. Given the endurance of the crisis, there is no chance of going back to the pre-election status quo, no matter what some of the Armenian authorities may want or claim. ${ }^{7}$ Second, the post-election crisis only revealed and confirmed the growing level of discontent, frustration, and anger over the mounting inequalities and disparities of wealth and income (and power) in today's Armenia. The crisis also serves to exert continuing pressure on the Armenian government, as the level of popular discontent has been awakened.

\section{A Political Crisis of Confidence}

The most important impact of the post-election crisis in Armenia is the fact that, after eight years of holding the country's highest post, former President Robert Kocharian bequeathed his successor a dangerous legacy of distrust and discontent. In this way, current Armenian President Serzh Sarkisian has inherited a genuine "crisis of confidence" marked by a loss of public trust and driven by a popular demand for change. In this way, the most basic obstacle facing the Armenian government is that it is operating in a distinctly new political context, insofar as the population has emerged from years of apathy to voice fresh and strident demands for change. For the current Armenian political reality, this negates any possibility of returning to the pre-crisis status quo, as the Armenian people have expressed a new sense of empowerment and a new demand for real change.

A related obstacle stems from the closed nature of the Armenian political system itself, where political opposition is perceived as a direct threat to the state, rather than as characteristic of a healthy and vibrant democracy. Armenia's current political system also lacks any mechanism for the normal expression of political dissent or popular discontent, a deficiency that only exacerbates underlying tensions. Moreover, the Armenian government must now learn to govern, and not just rule the country. But it remains hindered by its own internal weakness, and is undermined by its lack of legiti-

5 Richard Giragosian, "Legacy of Discontent: Assessing the Impact of March $1^{\text {st }}$," ArmeniaNow.com (1 March 2009).

6 Liz Fuller, “Armenia: Election Campaign Gets Off to Uneasy Start,” Radio Free Europe/ Radio Liberty (19 April 2007).

7 Emil Danielyan, “Armenian Strife Still an Open Wound One Year On,” RFE/RL Armenia Report (27 February 2009). 
macy and an absence of any real popular mandate. This not only calls into question the authority of the state, but also seriously erodes the government's capacity to implement the difficult policies needed to satisfy mounting demands for change and expectations for reform. Most troubling, Armenia now faces an increasingly serious combination of political and economic crises that raise new, very serious concerns over stability and security in the medium term.

\section{Armenia at a Strategic Crossroads}

As a result of these many challenges, Armenia is clearly approaching a strategic crossroads, where the future course of the nation's political and economic development faces two stark alternatives. The first of these two possible alternatives is to adopt a painful (but long overdue) set of policies to fully confront the systemic deficiencies of the country's democratic deficit, combat entrenched corruption, and move against the powerful commodity-based cartels and semi-monopolies that have come to dominate Armenia's fragile economic and political structures. Such a positive alternative necessitates a new-found political will, however, and needs to be bolstered by a more resilient and effective rule of law, neither of which have been evident in Armenia over the past several years.

The second alternative for the future trajectory of Armenia's economic and political development is a much more negative and shortsighted response, whereby the Armenian authorities adopt even more repressive and authoritarian policies. Such an alternative, modeled more on the course taken by Belarus or Russia, may be attractive to the Armenian authorities in the short term, reflecting their inherent lack of legitimacy and the propensity to view any dissent or opposition as a direct threat to their power and authority. Yet, over the medium term, such a reliance on authoritarian measures would only provoke a more dynamic reaction from both the country's newly united opposition and a much less apathetic population.

For Armenia, and for the South Caucasus region as a whole, the real imperatives are internal in nature, stemming from several key challenges: the need for elections driven by politics instead of power, and leadership determined more by election than selection. But most crucial is the lesson that legitimacy is the key determinant of durable security and stability, while the strategic reality of the region is defined less by geopolitics, and more by local politics and economics. 
SUMMER 2009

\section{Bibliography}

Armenia: Picking up the Pieces In ICG Europe Briefing. International Crisis Group (ICG), 2008.

Danielyan, Emil. Armenian Strife Still an Open Wound One Year On. RFE/RL Armenia Report, 2009.

Fuller, Liz. Armenia: Election Campaign Gets Off to Uneasy Start. Radio Free Europe/Radio Liberty, 2007.

Giragosian, Richard. Legacy of Discontent: Assessing the Impact of March 1st. ArmeniaNow.com, 2009.

Giragosian, Richard. Weathering the Storm: A Commentary on Armenia and the Global Economic Crisis. ArmeniaNow.com, 2009.

Giragosian, Richard. Weathering the Storm: A Commentary on Armenia and the Economics of Power. ArmeniaNow.com, 2009. 